\title{
sciendo
}

DOI 10.2478/sbe-2019-0033

SBE no. 14(2) 2019

\section{ARE CRYPTOCURRENCIES GOOD INVESTMENTS?}

\section{SHEETS BEN}

School of Business, Indiana University Kokomo, Kokomo, IN, USA

WANG XIAOQIONG

School of Business, Indiana University Kokomo, Kokomo, IN, USA

\begin{abstract}
:
This paper provides a comprehensive overview of cryptocurrencies, including the origin of cryptocurrencies, how cryptocurrencies operate, and the current situation of cryptocurrencies. In addition, we also provide the performance comparison of major cryptocurrencies with the performance of the stock market indexes. All the cryptocurrencies exhibit higher average returns and volatility than the stock market indexes, which appeals to risk-taking investors. We then perform additional analysis on the determinants of cryptocurrencies returns. We show that major fundamental variables are less likely to affect the returns of cryptocurrencies except for the S\&P 500 index returns and the exchange rates between U.S. dollars and Euros.
\end{abstract}

Key words: Cryptocurrencies, Market Indexes, Fundamentals, Performance

\section{Introduction}

A cryptocurrency or cryptocoin is a digital/electronic asset that holds value and works as a medium of exchange. Cryptocurrencies can be utilized for online or peer-topeer transactions without requiring the use of a central server to verify transactions (Figure 1). There are over 1,800 cryptocurrencies available on the market (Frankel, 2018) with the most notable being Bitcoin. Because cryptocurrencies are mediums of exchange, they can be accessed through online currency exchanges, where investors' dollars are converted to the cryptocoin of their choice. For example, when Bitcoin costs $\$ 8,000$ per unit, one dollar could be exchanged for 0.000125 Bitcoin. Examples of the U.S. cryptocurrency exchanges are Coinbase, BitFinex, BitStamp, and Gemini (Rosic, 2017).

The creation of the first cryptocurrency, Bitcoin, was derived from the need of a decentralized transaction network. This network would enable people from anywhere in the world to make direct peer-to-peer transactions without the need for a central server. The technology that was invented by Satoshi Nakamoto to enable Bitcoin to work is called block chain. Each block in the chain is a series of records, which stores a hash of each 
previous block (Marr 2017). This is the key feature that allows block chain to work without a central server. It applies specific conditions for validation, such as having the correct electronic signature, and any blocks missing any information will be rejected.

\section{Figure 1: Traditional vs Nontraditional Currency Networks}
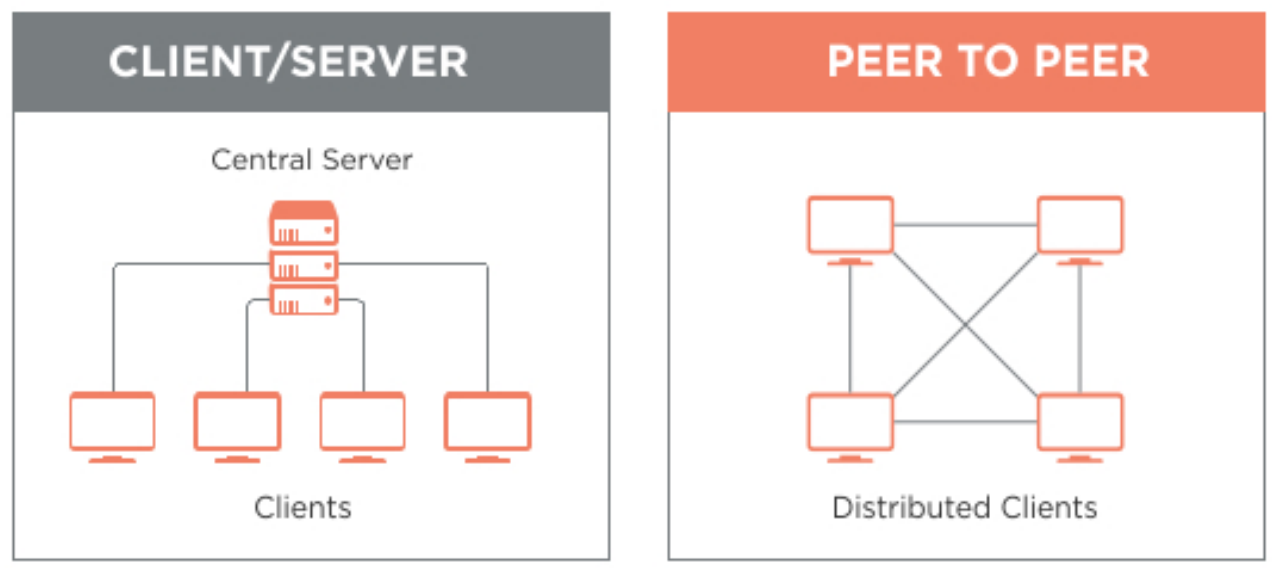

(Source: Lewis, 2015)

The information stored in the chains is usually financial information. In the case of cryptocurrencies and Bitcoin, it contains the records of the specific coins, such as when they were spent and traded. This allows the system to prevent double spending and fraud. In 2009, when Nakamoto first invented Bitcoin, it was known by very few people for 2 years. In 2011, two competing cryptocoins (Namecoin and Litecoin) were emerging. With the invention of these two coins, Bitcoin began to gain media attention. As it gained popularity, its value began to soar. In 2013 , it reached $\$ 1,000$ before its bubble popped and it crashed down to $\$ 200$. By 2016, cryptocurrencies were gaining more attention and companies started to have initial coin offerings (ICO) similar to Initial Public Offering (IPO) in the stock markets. Ethereum was the first coin to be released with an ICO (Marr, 2017). In 2017, Bitcoin was able to hit the $\$ 10,000$ mark, continued to climb, and peaked at just under $\$ 20,000$. It then began a slow decline and has continued to fall, hovering around $\$ 6,000$ per unit. Meanwhile, other cryptocurrencies have experienced similar declines.

The creators of IOTA, a cryptocoin, have developed a new technology called "The Tangle". This network functions similar to the block chain network. It utilizes the users for peer-to-peer confirmation. However, it is different because instead of having orderly hashes in a row, they are scrambled, making it even more encrypted. From the original point, "genesis", new transactions can be added and when they are added, the transaction chooses two previous transactions to confirm. If a transaction in the tangle is unapproved yet, it is referred to as a "tip". When a tip is later verified, it becomes another approved transaction (Gal, 2018). Figure 2 is a demonstration of the IOTA tangle. The point zero, genesis, is the original transaction with an IOTA coin, that all other nodes encrypt back to. 
As more transactions are confirmed, scrambled nodes fill the tangle. Not all the nodes lead back to the genesis point. These extra nodes are used for encryption, and this scrambled method is unique to IOTA and its tangle.

\section{Figure 2: IOTA Tangle}

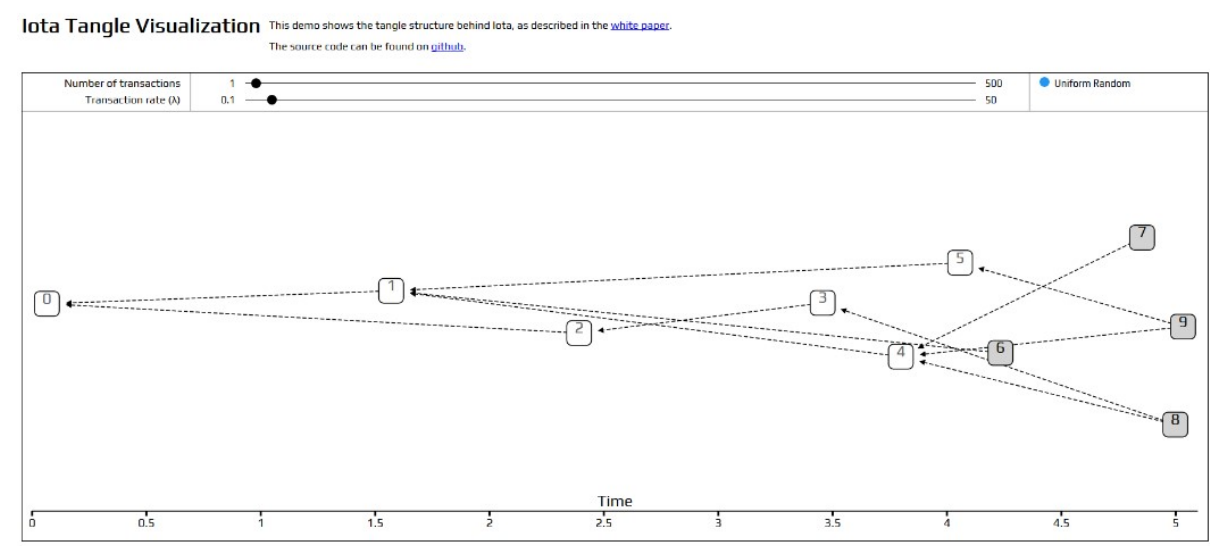

(Source: Gal, 2018)

Governments have had mixed reactions to cryptocurrencies. In 2016, the Securities and Exchange Commission (SEC) was skeptical of the technology and warned that they could be frauds. China took a harsher approach and banned cryptocurrencies all together (Morgan, 2018). The U.S. government is currently working on fixing the grey area that cryptocurrencies fall under with new regulations that would better define who regulates them. Currently, cryptocurrencies fall into the following jurisdictions: The Securities Exchange Commission (SEC), the Commodity Futures Trading Commission (CFTC), the Treasury Department, the Federal Reserve, and individual states. While some states are hesitant to accept cryptocurrency, or confused about what to consider it, and others embrace it. For instance, Arizona passed senate bill 1091, which allows crypto to be recognized by their Department of Revenue.

Cryptocurrencies are derived from confirmed transactions by miners on the chosen cryptocurrencies server. A miner is the person who donates the processing power of the computer to software platform that verifies all transactions of the specific coin. For most coins, block chain needs the power to be able to confirm the transactions in its records, and for the donated use of the power. When the system is finally able to confirm a record; the miner is rewarded with one single coin of the cryptocurrency that is mined for (Lewis, 2015).

With the surge of Bitcoin at the beginning of 2018, there are extant news, reports, and research about virtual currencies or cryptocurrencies. As for the industry, cryptocurrencies have been reported by major journals, such as the Wall Street Journal, Bloomberg, Yahoo Finance, and the Economist. With respect to academic research, Dyhberg (2016) show that Bitcoin can be used to hedge against stocks in the Financial Times Stock Exchange Index and against U.S. dollars in the short term. In addition, Baek 
and Elbeck (2014) provide evidence that Bitcoin volatility is internally driven, implying that the Bitcoin market is highly speculative. Even though cryptocurrencies have become a hot topic and are widely covered, little is known and researched about this category of "currencies". Thus, the purpose of this paper is to perform a comprehensive study on cryptocurrencies.

We first show that that the indexes are much safer investment than the cryptocurrencies. The cryptocurrencies have higher mean monthly returns than the indexes. For an investor who does not want to bear risk, investing in an index fund will provide a safer investment than investing a cryptocurrency. We then investigate what drives the returns of the cryptocurrencies. We consider several fundamental variables, including Consumer Price Index (CPI), Industrial Production Index, Real Personal Consumption Expenditures, 10 Year T-bill Rate, US-EURO Exchange Rate, and Unemployment rate. We find that other fundamental variables are less likely to affect the returns of cryptocurrencies except for the S\&P 500 index and the exchange rates between U.S. dollars and Euros.

This paper is organized as follows. Section 2 describes the data. Section 3 provides findings and analysis of the empirical results. Section 4 discusses the future of cryptocurrencies and the final section concludes.

\section{Data}

Using Yahoo Finance, monthly-adjusted close prices are collected for the ten cryptocurrencies: Bitcoin, Ethereum, Litecoin, Bitcoin Cash, Stellar, Monero, IOTA, Ripple, Cardano, and EOS. We also obtain adjusted close historical prices for the indexes: S\&P500, NASDAQ, NYSE Composite, Dow Jones, and Russell 2000. The sample period for each cryptocurrency is from the day that it became available on the market. The five indexes data begins in August 2010, the year that Bitcoin was first introduced. We compute monthly returns using the following equation,

$$
\text { Return }=\frac{\text { Adjusted Close Current Month }}{\text { Adjusted Close Previous Month }}-1
$$

The monthly data for Consumer Price Index (CPI), Industrial Production Index, Real Personal Consumption Expenditures, 10 Year T-bill Rate, US-EURO Exchange Rate, and Unemployment rate is collected from the Federal Reserve Bank of St. Louis (FRED).

\section{Empirical Results}

\subsection{Performance Evaluation}

After we compute monthly returns for the currencies and indexes, we calculate the sample standard deviation from the monthly returns. The information that can be extrapolated with the standard deviation is the volatility of each currency and index. When the standard deviation is high, the variance in price will be high. Higher standard deviation and higher variance proxy for higher risk. The monthly returns of the cryptocurrencies and the indexes are plotted as shown in Figures 3 and 4. As displayed in Figure 3, the returns 
patterns of the five indexes follow almost the same trend, rising and falling together. This trend is most notable in Figure 3 during $7 / 1 / 2015$ and 3/1/2016. On 7/1/2015, the five index returns begin a sharp rise from -0.05 return range and climb to 0.1 by 11/1/2015. Immediately after hitting this peak, the indices fall to -0.075 almost identically. After $7 / 1 / 2016$, the variation between the indices becomes greater. For instance, on 11/1/16, when the Russell 2000 reaches the 0.1 return threshold, the remaining indices, NASDAQ, Dow Jones, NYSE Composite, and the S\&P 500 remain at 0.05 returns or lower.

Figure 3: Index Returns

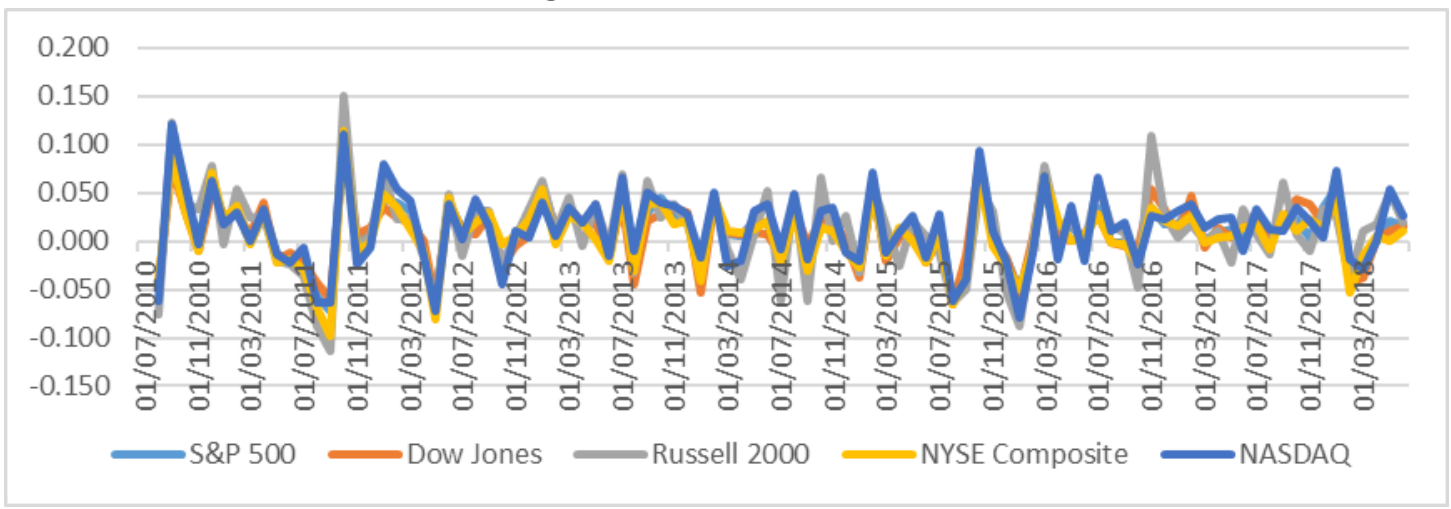

In Figure 4, the cryptocurrency returns are plotted. Most of the cryptocoins are developed recently, so Bitcoin is the dominate coin on most of this graph. As the years progress to 2017, all the coins are incorporated. The volatility of the cryptocoins reaches the highest rates on $2 / 1 / 2017$ and $10 / 1 / 2017$. The coins only briefly hit these high returns before crashing back down each time. In addition, all the cryptocurrencies exhibit significant fluctuation.

Figure 4: Cryptocurrency Returns

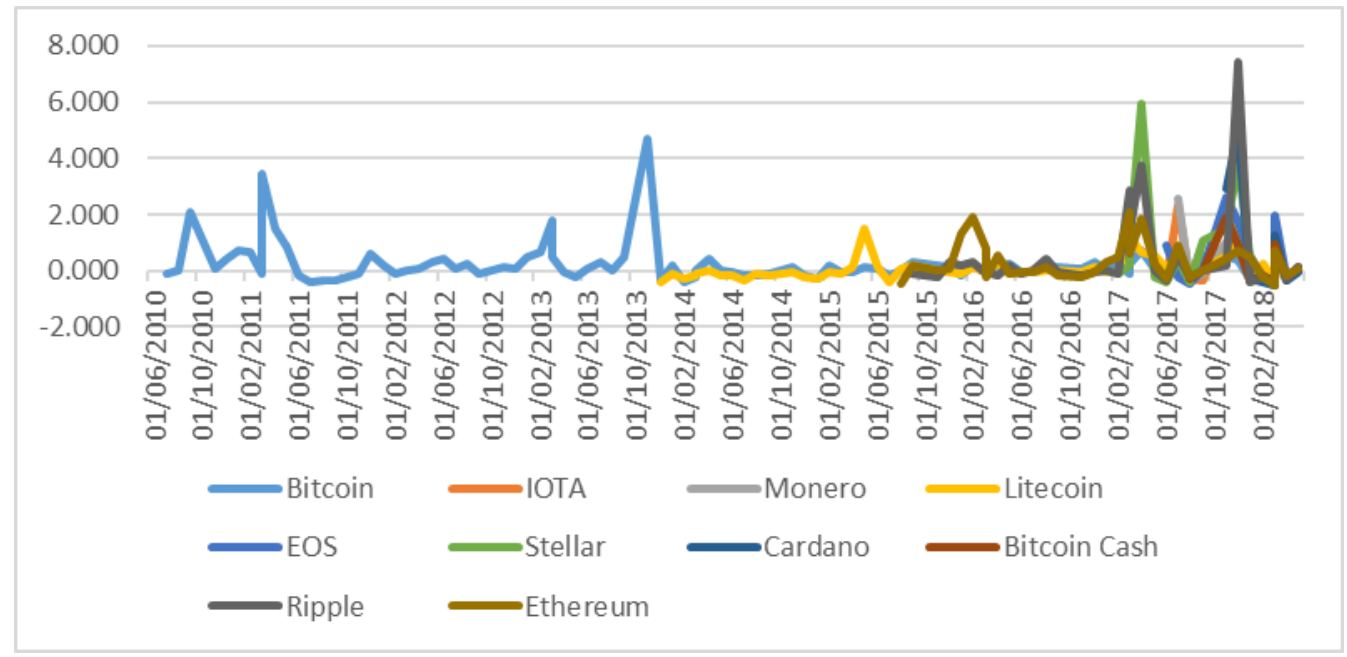


Table 1 summarizes the index performance. As reported in Table 1, the S\&P 500 has a mean of $1.02 \%$. The Dow Jones has a mean of $0.96 \%$. The third largest mean of the indices is the Russell 2000 with $1.09 \%$. The NYSE Composite has the lowest mean with $0.68 \%$. Finally, the largest mean of the indices is the NASDAQ with $1.37 \%$. The S\&P 500 has a standard deviation of $3.22 \%$. The Russell 2000 has the highest standard deviation with $4.50 \%$. The Dow Jones has a standard deviation of $3.17 \%$. And the NYSE Composite has a $3.40 \%$ standard deviation. Based on the findings, the safest 3 indexes are the S\&P 500 , the Dow Jones, and the NYSE Composite, by having the smallest sample standard deviation. This will provide a safe and low variance in the monthly return on the indexes, and investors in these indices will likely see slow return growth. This reduces the variance, making the indexes safe investment. The Russell 2000 is the riskiest index.

\section{Table 1 Indexes Summary Statistics}

\begin{tabular}{lllllll}
\hline Index Name & Sample Period & Mean & Median & $\begin{array}{c}\text { Standard } \\
\text { Deviation }\end{array}$ & Minimum & Maximum \\
\hline S\&P 500 & August 2010-June 2018 & $1.02 \%$ & $1.11 \%$ & $3.22 \%$ & $-7.18 \%$ & $10.77 \%$ \\
Dow Jones & August 2010-June 2018 & $0.96 \%$ & $0.82 \%$ & $3.17 \%$ & $-6.57 \%$ & $9.54 \%$ \\
Russell 2000 & August 2010-June 2018 & $1.09 \%$ & $1.51 \%$ & $4.50 \%$ & $-11.37 \%$ & $15.04 \%$ \\
NYSE Composite & August 2010-June 2018 & $0.68 \%$ & $0.94 \%$ & $3.40 \%$ & $-9.79 \%$ & $11.36 \%$ \\
NASDAQ & August 2010-June 2018 & $1.37 \%$ & $1.61 \%$ & $3.84 \%$ & $-7.86 \%$ & $12.04 \%$ \\
\hline
\end{tabular}

We report the sample mean and standard deviation of cryptocurrencies in Table 2. Starting with Bitcoin, the mean monthly return of Bitcoin is $23.30 \%$. Bitcoin outperforms any of the indices. The standard deviation of Bitcoin is $70.08 \%$. This high deviation represents significant fluctuation of the returns. The second cryptocoin is Ethereum and has a $33.10 \%$ mean monthly return and a $65.11 \%$ standard deviation. Ripple has a mean monthly return of $46.40 \%$ and a standard deviation of $149.69 \%$. The cryptocurrency, Bitcoin Cash, has a mean at $23.73 \%$. Bitcoin Cash also has a standard deviation of $72.36 \%$. The fifth coin is EOS, having a mean monthly return of $53.23 \%$ and a standard deviation of $99.41 \%$. Litecoin has a mean monthly return of $8.20 \%$ and standard deviation of $42.51 \%$. The sixth cryptocurrency is Cardano and has a mean monthly return of $94.56 \%$ and standard deviation of $187.61 \%$. Stellar has a mean monthly return of $79.47 \%$ and a standard deviation of $165.50 \%$. The penultimate coin, IOTA, has a mean monthly return of $42.54 \%$ and a standard deviation of $103.54 \%$. The final cryptocoin is Monero and has a mean monthly return of $32.72 \%$ and a standard deviation of $83.55 \%$. The crypto coins have much higher standard deviations. The mean monthly returns are also high, but the returns shows substantial monthly variation.

\begin{tabular}{|c|c|c|c|c|c|c|}
\hline \multicolumn{4}{|l|}{ Cryptocurrency } & \multicolumn{3}{|l|}{ Standard } \\
\hline Name & Sample Period & Mean & Median & Deviation & Minimum & Maximum \\
\hline Bitcoin & August 2010-June 2018 & $23.30 \%$ & $7.48 \%$ & $70.08 \%$ & $-38.87 \%$ & $470.94 \%$ \\
\hline IOTA & July 2017-June 2018 & $42.54 \%$ & $-14.88 \%$ & $103.54 \%$ & $-42.16 \%$ & $234.35 \%$ \\
\hline Monero & August 2017-June 2018 & $32.72 \%$ & $4.47 \%$ & $83.55 \%$ & $-36.73 \%$ & $255.39 \%$ \\
\hline Litecoin & January 2014-June 2018 & $8.20 \%$ & $-3.61 \%$ & $42.51 \%$ & $-42.56 \%$ & $163.58 \%$ \\
\hline
\end{tabular}




\begin{tabular}{lllllll} 
EOS & July 2017-June 2018 & $53.23 \%$ & $11.64 \%$ & $99.41 \%$ & $-45.72 \%$ & $262.89 \%$ \\
Stellar & February 2017-June 2018 & $79.47 \%$ & $18.85 \%$ & $165.50 \%$ & $-39.14 \%$ & $594.48 \%$ \\
Cardano & December 2017-June 2018 & $94.56 \%$ & $-15.36 \%$ & $187.61 \%$ & $-50.49 \%$ & $497.64 \%$ \\
Bitcoin Cash & September 2017-June 2018 & $23.73 \%$ & $-9.70 \%$ & $72.36 \%$ & $-42.89 \%$ & $188.49 \%$ \\
Ripple & October 2015-June 2018 & $46.40 \%$ & $-1.55 \%$ & $149.69 \%$ & $-43.49 \%$ & $740.41 \%$ \\
Ethereum & October 2015-June 2018 & $33.10 \%$ & $11.23 \%$ & $65.11 \%$ & $-53.72 \%$ & $210.58 \%$ \\
\hline
\end{tabular}

Comparing indices and cryptocurrency data, we can conclude that the indices are much safer investment than the cryptocurrencies. The cryptocurrencies have higher mean monthly returns than the indices. However, Bitcoin also has a standard deviation of $70.08 \%$, which leads to the large variances and risks in the individual monthly returns from the sample data. Stellar is the most volatile of all the cryptocurrencies and indices since it has a standard deviation of $165.50 \%$, which causes the larger variance of returns month to month. For an investor who does not want to bear risk, investing in an index fund provides a safer investment than investing a cryptocurrency. While an index does not have the same eye-catching monthly returns, it does bear less risk because the standard deviation is lower, which means a smaller price variance.

The cryptocurrency is an option for risk seeking investors. As stated, the high standard deviation leads to high volatility. High risk adverse investor will not bear this risk but the risk seeking investor will. Most cryptocurrencies have mean monthly returns of over $10 \%$, and standard deviations above $30 \%$, risk-seeking investors can expect high volatility from the price variance, which can lead to a large loss or gain for investors.

In conclusion, all five indexes are safer investments over the period than the crypto currencies. The cryptocurrencies, however, have much higher mean monthly returns than the indices. The indexes perform predictably over the period; the low standard deviation alleviates most of the risk that is involved in them. The low mean monthly return is another contributing factor to the conclusion. The cryptocurrencies are the most risky investments. Monthly returns of the cryptocurrencies can exceed $50 \%$ or more in any given month, adversely it can also fall by the same amount the following month. This demonstrates the high volatility of the cryptocurrencies. If an investor is risk adverse then cryptocurrencies are not good investments because of the possible losses. However, if an investor is risk seeking, then the cryptocurrencies are great investment because of possible gains.

\subsection{What Drives Cryptocurrency Returns?}

So far, we have documented and compared the returns and standard deviations of cryptocurrencies and indexes. In this section, we introduce several fundamental economic factors to investigate what drives the returns of the cryptocurrencies. Due to the short sample period of most cryptocurrencies, our regression analysis primarily concentrates on the following four cryptocurrencies: Bitcoin, Litecoin, Ripple, and Ethereum. We perform the following regression analysis:

$$
\begin{gathered}
R_{i, t}=\beta_{0}+\beta_{1} C P P_{i, t}+\beta_{2} I P I_{i, t}+\beta_{3} R_{P C E_{i, t}}+\beta_{4} S \& P 500_{i, t}+\beta_{5} U_{S D E U R O}, t \\
+\beta_{6} T N_{i, t}+\beta_{7} \text { Unemployment }_{i, t}+\varepsilon_{i, t}
\end{gathered}
$$

where $R_{i, t}$ represents returns of the cryptocurrencies. $C P l_{i, t}$ measures consumer price index; $I P I_{i, t}$ measures industrial production; $R P C E_{i, t}$ is real personal consumption expenditures; $S P 500_{i, t}$ measures in SP500 index returns; USDEURO $O_{i, t}$ is the exchange 
rate between U.S. dollars and Euros; $T N_{i, t}$ is the yield of 10-year Treasury note; Unemployment $i, t$ is the unemployment rate. All these variables proxy for the macroeconomic condition factors and the cryptocurrency market factor. The purpose of this test is to examine how the cryptocurrency market is influenced by macroeconomic conditions. The regression results are displayed in Table 3 for the four cryptocurrencies, respectively.

\begin{tabular}{|c|c|c|c|c|c|}
\hline \multicolumn{6}{|c|}{ Panel A Bitcoin } \\
\hline \multicolumn{2}{|c|}{ Regression Statistics } & & & & \\
\hline Multiple R & 0.345 & & & & \\
\hline R Square & 0.119 & & & & \\
\hline Adjusted R Square & 0.047 & & & & \\
\hline Standard Error & 0.691 & & & & \\
\hline \multirow[t]{2}{*}{ Observations } & 94 & & & & \\
\hline & Coefficients & $t$ Stat & $P$-value & Lower 95\% & $\begin{array}{c}\text { Upper } \\
95 \%\end{array}$ \\
\hline Intercept & 8.938 & 0.63 & 0.53 & -19.20 & 37.07 \\
\hline $\mathrm{CPI}$ & 0.032 & 0.28 & 0.78 & -0.20 & 0.27 \\
\hline IPI & -0.076 & -1.05 & 0.30 & -0.22 & 0.07 \\
\hline RPCE & 0.000 & -0.53 & 0.60 & 0.00 & 0.00 \\
\hline S\&P500 & 4.221 & 1.88 & 0.06 & -0.25 & 8.69 \\
\hline USDEURO & 0.291 & 0.16 & 0.87 & -3.30 & 3.88 \\
\hline TN & 30.552 & 1.48 & 0.14 & -10.36 & 71.47 \\
\hline Unemployment & -16.060 & -0.46 & 0.65 & -85.29 & 53.17 \\
\hline
\end{tabular}

\begin{tabular}{lr}
\hline \multicolumn{2}{c}{ Regression Statistics } \\
\hline Multiple R & Panel \\
R Square & 0.445 \\
Adjusted R Square & 0.198 \\
Standard Error & 0.076 \\
Observations & 0.416 \\
\hline
\end{tabular}

\begin{tabular}{lrrrrr}
\hline & Coefficients & \multicolumn{1}{c}{ S Stat } & P-value & Lower 95\% & \multicolumn{1}{c}{ Upper } \\
\hline Intercept & 0.917 & 0.06 & 0.95 & -28.17 & 30.01 \\
CPI & -0.042 & -0.20 & 0.84 & -0.46 & 0.38 \\
IPI & -0.008 & -0.15 & 0.88 & -0.11 & 0.09 \\
RPCE & 0.000 & 0.33 & 0.74 & 0.00 & 0.00
\end{tabular}




\begin{tabular}{lrrrrr} 
S\&P500 & 0.403 & 0.19 & 0.85 & -3.76 & 4.57 \\
USDEURO & -1.298 & -0.82 & 0.42 & -4.48 & 1.89 \\
TN & 29.824 & 0.96 & 0.34 & -32.99 & 92.63 \\
Unemployment & 2.921 & 0.06 & 0.95 & -91.58 & 97.42 \\
\hline
\end{tabular}

\section{Panel C Ripple}

\begin{tabular}{lr}
\hline \multicolumn{2}{c}{ Regression Statistics } \\
\hline Multiple R & 0.445 \\
R Square & 0.198 \\
Adjusted R Square & 0.076 \\
Standard Error & 0.416 \\
Observations & 54 \\
\hline
\end{tabular}

\begin{tabular}{lrrrrr}
\hline & Coefficients & t Stat & P-value & Lower 95\% & \multicolumn{1}{c}{$95 \%$} \\
\hline Intercept & 0.917 & 0.06 & 0.95 & -28.17 & 30.01 \\
CPI & -0.042 & -0.20 & 0.84 & -0.46 & 0.38 \\
IPI & -0.008 & -0.15 & 0.88 & -0.11 & 0.09 \\
RPCE & 0.000 & 0.33 & 0.74 & 0.00 & 0.00 \\
S\&P500 & 0.403 & 0.19 & 0.85 & -3.76 & 4.57 \\
USDEURO & -1.298 & -0.82 & 0.42 & -4.48 & 1.89 \\
TN & 29.824 & 0.96 & 0.34 & -32.99 & 92.63 \\
Unemployment & 2.921 & 0.06 & 0.95 & -91.58 & 97.42 \\
\hline
\end{tabular}

\section{Panel D Ethereum}

\begin{tabular}{lr}
\hline \multicolumn{2}{c}{ Regression Statistics } \\
\hline Multiple R & 0.541 \\
R Square & 0.293 \\
Adjusted R Square & 0.095 \\
Standard Error & 0.637 \\
Observations & 33 \\
\hline
\end{tabular}

\begin{tabular}{lrrrrr}
\hline & Coefficients & \multicolumn{1}{c}{ Stat } & P-value & Lower 95\% & \multicolumn{1}{c}{$95 \%$} \\
\hline Intercept & 36.063 & 1.06 & 0.30 & -34.16 & 106.28 \\
CPI & -0.158 & -0.32 & 0.75 & -1.17 & 0.86 \\
IPI & -0.002 & -0.01 & 0.99 & -0.40 & 0.40 \\
RPCE & 0.000 & -0.08 & 0.94 & -0.01 & 0.01 \\
S\&P500 & -0.150 & -0.03 & 0.97 & -9.03 & 8.73 \\
USDEURO & -8.037 & -1.97 & 0.06 & -16.44 & 0.36 \\
TN & 47.723 & 0.67 & 0.51 & -99.53 & 194.98 \\
Unemployment & -147.231 & -1.01 & 0.32 & -448.66 & 154.20 \\
\hline
\end{tabular}


As shown in Panel $\mathrm{A}$ of Table 3, the adjusted $\mathrm{R}$ square is $4.7 \%$, indicating that the fundamental variables explain $4.7 \%$ of the variation in returns of Bitcoin. Among all the variables, the coefficient of S\&P500 is 4.221 and statistically significant while other variables remain insignificant. The evidence suggests that the returns of Bitcoin are substantially affected by the stock market. With respect to Litecoin and Ripple as shown in Panels $B$ and $C$, none of the fundamental variables seems to significantly influence the return movement of Litecoin and Ripple. In the last panel, the coefficient of USDEURO appears to be significantly negative, implying the returns of Ethereum move in different directions with the exchange rate between U.S. dollars and Euros. Overall, other fundamental variables are less likely to affect the returns of cryptocurrencies except for the S\&P 500 index and the exchange rates between U.S. Dollars and Euros.

\section{The Future of Cryptocurrencies}

The volatility of cryptocurrencies makes their future uncertain. The lucrative returns that cryptocurrencies can offer are appealing to investors. However, the losses that can also be associated with cryptocurrencies drive some investors away. The underlying idea to cryptocoins is to have a decentralized peer-to-peer network that does not require a bank or central authority. This allows for the instant transfer of value anywhere in the world, while maintaining a safe and secure transaction ledger so that the coins cannot be duplicated, and double spent.

Other speculators have suggested that Bitcoin and other cryptocurrencies have hit their peak prices and returns, and there will continue to be a downward fall in both price and returns. Goldman-Sachs has recently opened a trading desk for cryptocurrency. However, an investment team at Goldman-Sachs also predicts the downward trend. The chief investment officer Sharmin Mossavar-Rahmani says that, "Our view that cryptocurrencies would not retain value in their current incarnation remains intact and, in fact, has been borne out much sooner than we expected" (Wilmoth 2018). Investors who are risk adverse will not see cryptocurrencies as good investment options.

Tim Draper, founding partner in Draper Associates, believes that the cryptocurrency Bitcoin will make a large comeback. At Draper university, he predicted, "I'm thinking $\$ 250,000$ a Bitcoin by 2022" (Caster, 2018). This would be a monumental increase in the value of Bitcoin, eclipsing the previous high of $\$ 19,783.06$. This price hike would yield high returns and attract even more attention from investors. The potential increase in Bitcoin and other cryptocoins still offer investors who are risk seeking plenty of opportunity to invest.

Bitcoin will likely maintain its strong position compared to other cryptocurrencies. As shown in the regression analysis, the coefficient of S\&P 500 is significant. This should provide future investors the opportunity to invest while the stock market performs well. Litecoin, ripple, and other cryptocurrencies may surge if the price of Bitcoin does as well, but do not show direct statistical impact by market index returns, consumer price index, real personal consumption expenditures, and other fundamental variables. 


\section{Conclusion}

To summarize, we investigate the performance of ten cryptocurrencies: Bitcoin, Ethereum, Litecoin, Bitcoin Cash, Stellar, Monero, IOTA, Ripple, Cardano, and EOS and compare their performance with the major U.S. market indexes. We show significant variation in the performance of cryptocurrencies. For instance, monthly returns of the cryptocurrencies can exceed $50 \%$ or more in any given month, adversely it can also fall by the same amount the following month. If an investor is risk adverse than cryptocurrencies are not good investments because of the possible losses. However, if an investor is risk seeking, then the cryptocurrencies are great investment, because of the potential gains. We also document that fundamental variables, including Consumer Price Index (CPI), Industrial Production Index, Real Personal Consumption Expenditures, 10 Year T-bill Rate, and Unemployment rate, are less likely to affect the returns of cryptocurrencies. Whereas the S\&P 500 index and the exchange rates between U.S. Dollars and Euros are significantly associated with the performance of cryptocurrencies.

\section{Acknowledgement:}

"This work was supported by the Indiana University Kokomo Summer Undergraduate Research Grant."

\section{References}

Baek, C., and Elbeck, M., (2015), Bitcoins as an investment or speculative vehicle? A first look, Applied Economics Letters, Vol. 22, no.1, pp. 30-34.

Caster, A. (2018), Tim Draper Predicts Bitcoin Will Soar to $\$ 250,000$ in 4 Years, Nasdaq, April, Available online at https://www.nasdaq.com/article/tim-draper-predicts-Bitcoin-will-soar-to250000-in-four-years-cm947882

Dyhrberg, A.H., (2016), Hedging capabilities of bitcoin. Is it the virtual gold?, Finance Research Letters, Vol. 16, pp. 139-144.

Frankel, M. (2018), How many cryptocurrencies are there?, The Motley Fool, March, Available online at https://www.fool.com/investing/2018/03/16/how-many-cryptocurrencies-are-there.aspx

Gal, A. (2018), The Tangle, Medium, January, Available online at https://blog.iota.org/the-tangle-anillustrated-introduction-4d5eae6fe8d4

IOTA Tangle Visualization, Available online at https://public-rdsdavdrpd.now.sh/

Lewis, A. (2015), A gentle introduction to blockchain technology, Bits on Blocks, September, Available online athttps://bitsonblocks.net/2015/09/09/gentle-introduction-blockchaintechnology/

Marr, B. (2017), A short history of Bitcoin and cryptocurrency everyone should read, Forbes, December, Available online at https://www.forbes.com/sites/bernardmarr/2017/12/06/ashort-history-of-Bitcoin-and-crypto-currency-everyone-should-read/3/\#46f3435961c7

Morgan, D. (2018), Congress sets sights on federal cryptocurrency rules, Reuters, February, Available online athttps://www.reuters.com/article/us-crypto-currencies-congress/congresssets-sights-on-federal-cryptocurrency-rules-idUSKCN1G31AG

Rosic, A. (2017), How To Invest In Cryptocurrencies, Blockgeeks, July, Available online at https://blockgeeks.com/guides/how-to-invest-in-cryptocurrencies/ 
Tweed, D. (2018), Why governments might join the cryptocurrency crazy, Bloomberg, February, Available online at https://www.bloomberg.com/news/articles/2018-02-12/why-governmentsmight-join-the-cryptocurrency-craze-quicktake

Wilmoth, J. (2018), We Expect Future Bitcoin Price Declines: Goldman Sachs, CNN, August, Available online at https://www.ccn.com/we-expect-future-Bitcoin-price-declines-goldmansachs/

Zima, E. (2018), Cryptocurrency in government: Opportunity or headache?, Government Technology, March, Available online at http://www.govtech.com/computing/Cryptocurrencyin-Government-Opportunity-or-Headache.html 